\title{
OCORRÊNCIA DE AURICULA COMPLEXA (BACILLARIOPHYCEAE) NA PLATAFORMA CONTINENTAL DE PERNAMBUCO
}

\author{
Núbia Abrantes Gomes(1,3) \\ Enide Eskinazi-Leça $(2,3)$ \\ Maria da Glória Gonçalves da Silva-Cunha(2,3)
}

\begin{abstract}
RESUMO - Auricula complexa (Gregory) Cleve (Auriculaceae, Bacillariophyceae) é assinalada pela primeira vez para as águas costeiras de Pernambuco, NE do Brasil. A espécie foi encontrada em amostras de plancton, coletadas durante o período de março/87 a fevereiro/88, em quatro estaçōes, localizadas em um perfil perpendicular à costa. $\mathrm{O}$ trabalho fornece descrição, distribuição na área estudada e dados ecológicos da espécie, que esteve presente em nove das 48 amostras coletadas. Quantitativamente foi pouco representativa, com percentuais que não atingiram mais que $0,5 \%$ da população fitoplanctônica total.
\end{abstract}

Palavras Chaves: diatomácea - plancton - Pernambuco.

ABSTRACT - Auricula complexa (Gregory) Cleve (Auriculaceae, Bacillariophyceae) is mentioned for the first time to coastal waters of Pernambuco. Northeastern Brazil. The species was found in plankton samples collected from March/1987 to February/1988 in four stations located in a line perpendicular to the coast. Description, distribution in the area studied, and ecological data are givem. Auricula complexa (Gregory) Cleve was observed in 9 out of the 48 samples examined, with percentages not higher than $0,5 \%$ of the total phytoplancton population.

Key Words: diatom - plankton - Pernambuco.

\section{Introdução}

Estudos taxonômicos sobre diatomáceas(Bacillariophyceae) marinhas vêm sendo realizados no Departamento de Oceanografia da Universidade Federal de Pernambuco desde 1966 (ESKINAZI \& SATO, 1966). A partir daí, vários trabalhos foram publicados, existindo grande número de informações sobre a ocorrência dessas microalgas no litoral de Pernambuco (ESKINAZI-LEÇA, 1970; ESKINAZI-LEÇA \& PASSAVANTE, 1970; SILVA, 1982).

(1) Mestranda do Curso de Mestrado em Criptógamos da Universidade Federal de Pernambuco

(2) Departamento de Oceanografia, Universidade Federal de Pernambuco-Campus Universitário, CEP 50739, Recife - PE

(3) Bolsista do CNPq 
Em recente levantamento, MENEZES \& MOURA (1989) relacionaram o total de 230 espécies que ocorrem nos ecossistemas marinhos e estuarinos do Estado de Pernambuco.

No presente trabalho, amplia-se o número de espécies conhecidas ao relatar a ocorrência de Auricula complexa (Gregory) Cleve, complementando-se a informação com dados sobre sua distribuição anual e temporal na área.

\section{Consideraçōes sobre a Área Estudada}

O Litoral do Estado de Pernambuco tem a extensão de $187 \mathrm{Km}$ e estendese desde as praias de Carne de Vaca (Município de Goiana), divisa com o Estado da Paraíba até a praia de Queimada (Município de Barreiros), divisa com o Estado de Alagoas. A faixa litorânea está caracterizada pela presença de mangues e plantações de coqueiros, predominando o clima do tipo As' (segundo a classificação de Köppen), com temperatura do ar geralmente elevada e cuja média anual situa-se em torno de $26^{\circ} \mathrm{C}$. As temperaturas mais baixas correspondem aos meses de precipitações máximas, ou seja, entre junho e julho, enquanto que os meses mais quentes correspondem aos de janeiro a março (ANDRADE \& LINS, 1971).

Em toda a faixa costeira chove durante todo o ano caracterizando-se, entretanto, dois períodos anuais: um com precipitação mensal acima de $100 \mathrm{~mm}$, compreendido entre os meses de março a agosto e denominado período chuvoso e outro com precipitação abaixo de $100 \mathrm{~mm}$ mensais, compreendido entre setembro e fevereiro e chamado período seco (CAVALCANTI \& KEMPF, 1970).

$\mathrm{O}$ trecho onde as coletas foram realizadas localiza-se ao norte da plataforma continental de Pernambuco, está empreendido no paralelo 7041'30''S e os meridianos $34^{\circ} 46^{\prime} 50^{\prime \prime}$ e $34^{\circ} 34^{\prime} 00^{\prime \prime}$ e recebe influência das águas provenientes do canal de Santa Cruz. Segundo MACEDO \& COSTA (1988), esta influência é pequena e observada principalmente durante o período chuvoso, quando ocorre um ligeiro rebaixamento na transparência, na salinidade e na temperatura da água salientando-se, entretanto que estas variações não atingem locais mais afastados que 1,5 milha náutica da costa. A isoalina de $36 \%$ \% pode ser encontrada bem próximo da costa, notadamente durante o período seco, o mesmo acontecendo com a temperatura da água, que oscila entre $26,10^{\circ} \mathrm{C}$ e $30,80^{\circ} \mathrm{C}$. Portanto, o trecho estudado está caracterizado por uma certa uniformidade ambiental, tanto no sentido horizontal como no vertical, sendo apenas ligeiramente perturbada durante o período chuvoso.

A plataforma é estreita, medindo em torno de 20 milhas náuticas de largura e está coberta por sedimento calcário proveniente do acúmulo de algas calcárias do grupo das Melobesiae (KEMPF, 1970).

\section{Material e Métodos}

O material analisado constou de 48 amostras de plancton coletadas através de arrastos horizontais na superfície da água durante o período de março/87 a 
fevereiro/88. Os arrastos foram realizados com rede de malha de $60 \mu \mathrm{m}$ de abertura e em quatro estações localizadas em águas costeiras de Pernambuco.

Para identificação da espécie foram montadas lâminas permanentes, de acordo com o método de MÜLLER-MELCHERS \& FERRANDO (1956). As contagens para determinação da abundância relativa foram realizadas em subamostras de $0,5 \mathrm{~cm}^{3}$ retiradas após homogeinização da amostra total.

\section{Resultados}

Posição taxonômica (segundo KRIEGER, 1954 e HENDEY, 1964)

Divisão: Chrysophyta

Classe: Bacillariophyceae

Ordem: Biraphidales

Família: Auriculaceae

Gênero: Auricula

Espécie: Auricula complexa (Gregory) Cleve

Descriçâo: (fig.) Células solitárias, livres. Frústula retangular, ápices arredondados, ou fortemente elíptica para globular. Valva auricular, reniforme, quilha forte ao redor da margem dorsal, onde se localiza a rafe. Superfície valvar coberta com estrias radiantes, que partem da margem ventral para a dorsal e terminam sobre a quilha, formando uma fileira de pontos. Estrias $18-20 \mathrm{em}$ $10 \mu \mathrm{m}$.

Dimensões - comprimento: $106-112 \mu \mathrm{m}$

$$
\text { largura: } 47-52 \mu \mathrm{m}
$$

Os indivíduos analisados apresentam características morfológicas e métricas bastante semelhantes àquelas apresentadas por PERAGALLO \& PERAGALLO (1897-1908) e HENDEY (1964).

Ocorrência em Pernambuco: A fig. 2 apresenta a distribuição anual e espacial de Auricula complexa em águas costeiras de Pernambuco, observando-se ser esta uma espécie esporádica, sem ciclo anual definido. Nas quatro estações pesquisadas, o percentual de ocorrência apresentou sempre valores inferiores a $0,5 \%$, demonstrando ser uma espécie sem representação quantitativa significativa durante o ano.

\section{Discussäo e Conclusōes}

O gênero Auricula caracteriza-se pela forma reniforme ou auricular das valvas e rafe deslocada do eixo apical para uma quilha localizada próxima do bordo das valvas. Por muito tempo, o gênero esteve localizado na família Naviculaceae, em virtude da simetria valvar próxima da encontrada em Amphora e Amphiprora. Entretanto, HENDEY (1964) considerando a simetria incomum da frústula e a posição da rafe decidiu pela criação de uma nova família, Auriculaceae, para melhor enquadramento do referido gênero. Para isto, baseou-se 
no fato dos representantes de Naviculaceae estarem caracterizados pela simetria dos eixos apical e transapical e em Auriculaceae as valvas serem simétricas apenas segundo o eixo transapical. Em Naviculaceae, a rafe tem posição axial e em Auriculaceae ocupa posição excêntrica, curvada e localizada numa quilha próxima do bordo valvar. No enquadramento da espécie presentemente identificada adotou-se o critério sugerido por HENDEY (1964). Segundo este autor, todos os representantes da família são marinhos, planctônicos ou neríticos, ocorrem tanto em mares temperados como tropicais e assinalou a ocorrência da espécie em águas costeiras das ilhas Britânicas.

NAVARRO (1983) considerou Auricula complexa uma espécie frequente nas águas costeiras de Porto Rico.

Nas amostras presentemente estudadas, Auricula complexa demonstrou ser uma espécie de pouca importância quantitativa. Entretanto, apesar dos baixos percentuais, foi encontrada durante todo o ano e nas quatro estações pesquisadas, parecendo ser uma espécie pouco representativa, porém, comum em vários pontos da costa.

Pelo levantamento bibliográfico realizado, a espécie parece não ter sido ainda citada para outros ecossistemas do Brasil, podendo-se, portanto, considerar o presente trabalho também como o de sua primeira ocorrência no país.

\section{Referências Bibliográficas}

ANDRADE, G. O. \& LINS, R. C. 1971. Os climas do Nordeste. In: VANCONCELOS SOBRINHO, J. ed. As regiões naturais do Nordeste; o meio e a civilização. CONDEPE, Recife, p. 95-138.

CAVALCANTI, L. B. \& KEMPF, M. 1970. Estudo da plataforma continental na área do Recife (Brasil), 2: meteorologia e hidrologia. Trab. Oceanog. Univ. Fed. Pernambuco, Recife, 9/11: 149-58.

ESKINAZI, E. \& SATO, S. 1966. Contribuição ao estudo das diatomáceas da praia de Piedade. Trab. Inst. Oceanog. Univ. Fed. Pernambuco, Recife, 5/6: 73-114.

ESKINAZI-LEÇA, E. 1970. Estudo da plataforma continental na área do Recife, 3: diatomáceas do fitoplancton. Trab. Oceanog. Univ. Fed. Pernambuco, Recife, 9/11: $159-72$.

- \& PASSAVANTE, J. Z. O. 1972. Estudo da plataforma continental na área do Recife, 4: aspectos quantitativos do fitoplancton. Trab. Oceanog. Univ. Fed. Pernambuco. Recife, 13: 93-103.

HENDEY, N. Y. 1964. An Introductory account of the smaller algae of British coast waters. Part V: Bacillariophyceae (diatoms) Otto Koeltz Science Pupl.. London, 317p.

KEMPF, M. 1970. A plataforma continental de Pernambuco (Brasil): nota preliminar sobre a natureza do fundo. Trab. Oceanog. Univ. Fed. Pernambuco, Recife. 9/11: 111-24.

KRIEGER, W. 1954, Chrysophyta. In: ENGLER, A.Sillabus der pflanzen-familien. Gebrüder Borntraeger, Berlim, 2- ed., vol. , part 7, p. 73-85.

MACÊDO, S.J. \& COSTA, K. M. P. 1988. Hidrologia. In: ESKINAZI-LEÇA, E. ed. Hidrologia e plancton na plataforma continental de Pernambuco. Dep. Oceanogr. UF$\mathrm{PE} / \mathrm{CNPq}$, Recife (Relatório Técnico-Científico).

MENEZES, L. A. \& MOURA, R. T. 1989. Diatomáceas do Estado de Pernambuco. Dep. 
Oceanogr. UFPE, Recife (mimeografado).

MUELLER-MELCHERS, F. C. \& FERRANDO, H. J. 1965. Tecnica para el estudio de las diatomeas. Bol. Inst. Oceanog. São Paulo, São Paulo, 7(1/2): 151-60.

NAVARRO, J. N. 1983. A survey of the marine diatoms of Puerto Rico, 7: Suborder Rhaphidineae: Families Auriculaceae, Ephithemiaceae. Nitzschiaceae and Surirelaceae. Bot. Mar., New York, 26:393-408.

PERAGALlO, H. \& PERAGALLO, M. 1897-1908. Diatomés marines de France et des districts maritimes voisines. J. Témpere, Paris, 491p.

SILVA, M. G. G. 1982. Distribuição das diatomáceas (Bacillariophyceae) na plataforma continental de Pernambuco (Brasil). Trab. Oceanogr. Univ. Fed. Pernambuco, Recife, 17: 7-46. 


\section{$20 \mu \mu$}

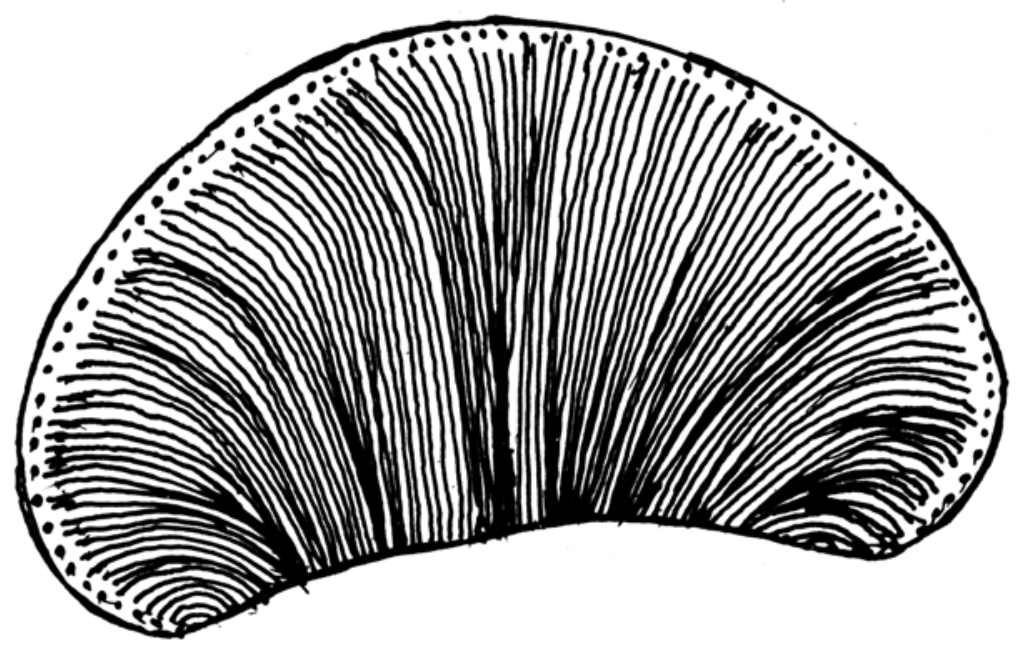

Fig. 1 - Auricula complexa (Gregory) Cleve: vista valvar. 


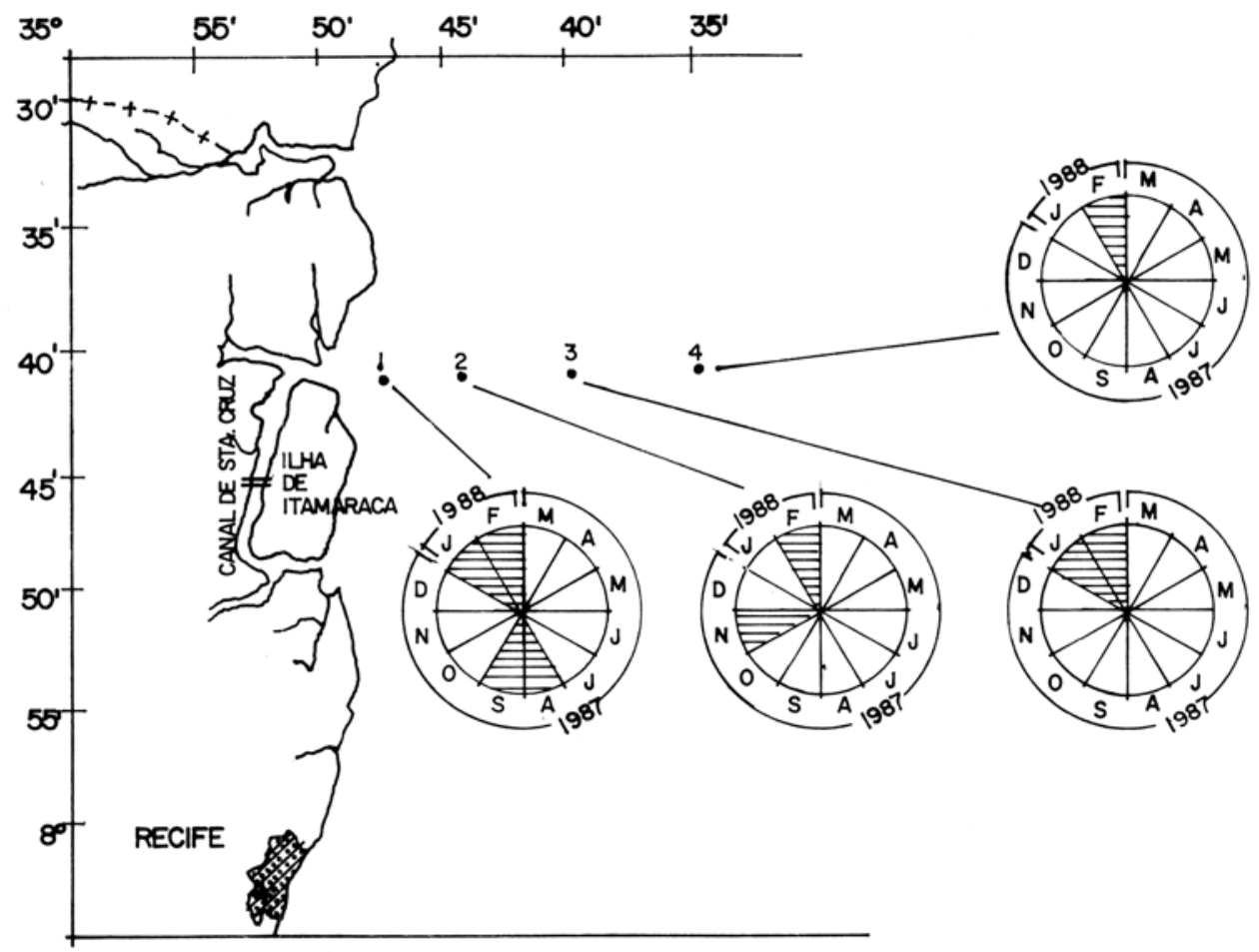

Fig. 2 - Distribuição de Auricula complexa (Gregory) Cleve em quatro estações na plataforma continental de Pernambuco. 